\title{
MYELOMENINGOCELE
}

\section{A Brazilian University Hospital experience}

\author{
Maria M.M. Ulsenheimer' ${ }^{1}$, Sérgio A. Antoniuk², \\ Lúcia H.C. dos Santos 3 , Marcos P. Ceccatto 4 , \\ Antônio Ernesto da Silveira ${ }^{5}$, Ana Paula Ruiz ${ }^{6}$, Paulo Egger ${ }^{7}$, Isac Bruck²
}

\begin{abstract}
We analyzed 31 children with myelomeningocele born between July 1990 and July 2000 . Followup median was 24 months (6-68months). Only 2 mothers had a known etiologic factor (diabetesmellitus). Twelve had the correct prenatal diagnosis. All children were born at term; 23 by cesarean; 13 had rupture of the membrane. Surgical correction had a 4 days median (1 to 44 days). Lumbosacral lesions were the most frequent (46\%). Thirty patients were hydrocephalic, shunt was placed in 27 . Meningitis was 4 times more frequent in shunted patients. Seven became epileptic (19.4\%). Denver II test showed significant delay in gross motor development. Neurogenic bladder was diagnosed in 12 patients. Congenital clubfoot was the main orthopedic malformation (53\%). Six infants died. Nowadays, 17 patients are being followed. A multidisciplinary approach probably helps for a better quality of life.
\end{abstract}

KEY WORDS: meningomyelocele, neural tube defects, neurological disabilities.

\begin{abstract}
Mielomeningocele: experiência de um hospital universitário brasileiro
RESUMO - Avaliamos 31 crianças com mielomeningocele nascidas entre julho de 1990 e julho de 2000. A mediana de acompanhamento foi 24 meses (6-68m). Duas mães possuíam conhecido fator de risco (diabetes mellitus). Doze obtiveram correto diagnóstico pré-natal da patologia. Todas as crianças nasceram a termo; 23 via cesariana; 13 apresentaram ruptura de membrana. A mediana de correção cirúrgica foi 4 dias (1-44d). Lesões lombosacras foram as mais freqüentes (46\%). Trinta pacientes apresentaram hidrocefalia, sendo a derivação ventrículo peritoneal (DVP) necessária em 27. Meningite foi 4 vezes maisfrequente em pacientes com DVP. Sete pacientes eram epilépticos (19,4\%). 0 teste de Denver II mostrou atraso motor significante. Bexiga neurogênica foi diagnosticada em 12 pacientes. Pé torto congênito foi a malformação ortopédica mais comum (53\%). Seis pacientes morreram. Até o momento, 17 pacientes são acompanhados. Uma abordagem multidisciplinar provavelmente colabora para melhor qualidade de vida.
\end{abstract}

PALAVRAS-CHAVE: mielomeningocele, defeitos do tubo neural, deficiências neurológicas.

Myelomeningocele has a frequency of approximately 1:1000 newborn alive, with preponderance in females and white race ${ }^{1,2}$. It is a neural tube defect (NTD) that results from a failure of closure of the neural tube during the fourth week of embryogenesis. It can occur since cervical until sacral region. Depending on the level of the lesion can cause different grades of neurological dysfunction ${ }^{2}$. Etiology is variable, involving both genetic and environmental factors, as for instance an inadequate level of folic acid during embryonary neuru- lation ${ }^{2-8}$. The cystic appearance noted at the spinal cord iseasy to diagnose at newborn period and must be repaired within 24 to 48 hoursto reduce the risk of infection. However, treatment is not limited to the closure of the NTD, since other systems show abnormalities, as urinary system, for example ${ }^{2}$.

Nowadays, with the advent of neonatal intensive care unit (ICU), antibiotics and new neurosurgery techniques, and high quality of the rehabilitation techniques, an increase in the life expectance of children with myelomeningocele has been ob-

Centro de Neurologia Pediátrica - CENEP, Departamento de Pediatria, Hospital de Clínicas de Curitiba, Universidade Federal do Paraná UFPR Curitiba, PR, Brazil: ${ }^{1}$ Pediatra do Departamento de Pediatria da UFPR; ${ }^{2}$ Neuropediatra, Professor Assistente do Departamento de Pediatria da UFPR; ${ }^{3}$ Neuropediatra, Professora Adjunta do Departamento de Pediatria da UFPR; ${ }^{4}$ Neonatologista, Professor Assistente do Departamento de Pediatria da UFPR; ${ }^{5}$ Cirurgião Pediátrico, Professor Adjunto do Departamento de Cirurgia da UFPR; ${ }^{6}$ Neuropediatra; ${ }^{7}$ Médico Cirurgião Pediátrico.

Received 12 February 2004, received in final form 2 June 2004. Accepted 6 J uly 2004.

Dr. Isac Bruck - Rua Floriano Essenfelder 81 - 80060-270 Curitiba PR - Brasil. E-mail: ibruck@terra.com.br 
served. Thus, it is important that the health care institutions and the society as a whole, be prepare to receive these children and offer them a better quality of life.

On this basis, we reviewed the patients with myelomeningocele born or transferred to the maternity of our hospital, to determine their clinical profile, the treatment approach offered to them, and their follow-up. Special attention was paid to neurological performance, and to determinig wether the children were able to walk and to acquire sphincter control.

\section{METHOD}

We reviewed the follow-up of neonates born in the maternity of University Hospital of Universidade Federal do Paraná between July 1990 and July 2000, as well as newborns with myelomeningocele transferred to Neonatal Intensive Care Unit (ICU) of our Hospital during the same period. The Ethical Committee of this Hospital approved the study.

Prenatal and neonatal data were reviewed from Neonatal ICU registers. Other data were collected from outpatients care register, accomplished by neurologic and surgical teams, composed by resident of third and fouth years under supervision of teachers of the respective disciplines.

We analyzed gender, race, family history, and maternal aspects that could have some relation with the occurrence of the disease (drugsin use, age, parity, educational level, prenatal care, and basic diseases), aswell astime of diagnosis (pre or post-natal), perinatal data (type of delivery, gestational age by Parkin, newborn weight, Apgar score, head circumference, orthopedic abnormalities), characteristics of the lesion (location, presence or not of membrane rupture, use of prophylactic antibiotics) and central nervous system (CNS) abnormalities, seen through computed tomography (CT) scan or ultrasonography (US), date of surgical correction and insertion of ventricle peritoneal shunt (VPS). The Denver II Screening test was used to assess the neuropsychomotor development of these patients up to the age of 2 years ${ }^{9,10}$. Other data related to neurological complications have also been indicated, such as: epilepsy, meningitis, VPS changes).

Urological follow-up estabilished at the outpatient dinic of pediatric surgery were also evaluated by means of imaging exams such as urography, echography or urodynamic evaluation; presence or not of neurogenic bladder, prophylactic use of antibiotics for infection of urinary tract, use of catheterization or not, sphincter control, ability to walk and renal function monitorization. Orthopedic deformations were also described.

\section{RESULTS}

A total of 36 cases of myelomeningocele were detected between 20369 liveborn infants at our ma- ternity between July 1990 and July 2000, equivalent to a prevalence of 1.8 cases/1000 liveborn infants.

The effective number of patients in the study was 31.26 of them originally from our maternity and 5 born in other maternities in the state and transferred to the neonatal ICU of our Hospital in the first few days of life. Ten patients born in our maternity were excluded because they didnot return to outpatient clinic for follow-up.

There was a frank preponderance of white race ( 29 patients $=93.5 \%$ ) but no difference in gender (16 females: 15 males). Mean maternal age was 25 years old (SD7.3 years). Educational level ranged from 1 to 11 years of study (mean $\pm \mathrm{SD}=7.7 \pm$ 3.7years). With respect to family origin, 10 were from Curitiba, 10 from metropolitan region of the dity and 11 from other towns in the State of Parana. Two mothers had diabetes mellitus during pregnancy, 1 epilepsy, 2 rheumatic disease, 2 cancer and 2 systemic hypertension. None of them made use of medication considered to cause myelomeningocele during pregnancy. Twenty five $(80.6 \%)$ cases occurred between the first and second pregnan$c y$, and there was one case with family history of first degree relatives. None of the women used folic acid as a mean to prevent NTD.

Twelve cases (39\%) were diagnosed prenatally. Ten other cases (32.2\%) had pre-natal diagnosis of hydrocephalus only, as part of NTD. Just one pregnant woman didnot receive prenatal care. In other $8(25 \%)$, there wasnot information about prenatal care on their registers.

Cesarean section was the preferential route of delivery $(23$ cases $=74 \%$ ). Similar percentage of ruptures of the myelomenigocele membrane occurred whether delivery was vaginal or cesarean section (10 among 23 cesarean sections $=43 \%$ and 3 in the 8 vaginal delivery $=37.5 \%$ ). Mean gestational age was 39 and a half weeks (SD 1 week), and mean infant weight was 3009gr (SD 573gr). The Apgar score was below 6 at 5 minutes in only one case.

Table 1. Associated central nervous system malformations.

\begin{tabular}{lc}
\hline Malformation & N (\%) cases \\
\hline Arnold Chiari II & $10(32.2 \%)$ \\
Corpus callosum agenesis & $4(12.9 \%)$ \\
Colpocephaly & $2(6.4 \%)$ \\
Holoprosencephaly & $2(6.4 \%)$ \\
Septum pellucidum defects & $1(3.2 \%)$ \\
\hline
\end{tabular}


Table 2. Neurological evaluation by Denver II at 12 months of age $(n=21)$.

\begin{tabular}{lcc}
\hline Area & Mean* & Standard deviation* \\
\hline Gross motor & 7 & 2 \\
Fine motor & 9.43 & 2.8 \\
Language & 10 & 2.3 \\
Personal-social & 10 & 2.53 \\
\hline in months & &
\end{tabular}

Table 3. Neurological evaluation by Denver II at 24 months of age $(n=13)$.

\begin{tabular}{lcc}
\hline Área & Mean* & Standard deviation* \\
\hline Gross motor & 15.6 & 6.9 \\
Fine motor & 22.1 & 4.37 \\
Language & 23 & 3.1 \\
Personal-social & 22.3 & 3.9 \\
\hline * in months & &
\end{tabular}

Mean head circumference at birth was $35.5 \mathrm{~cm}$ (SD $3.6 \mathrm{~cm})$. The level of the lesion wascervical in 2 cases $(6 \%)$, thoracolumbar in $10(32 \%)$, lumbar in 4 (13\%), lumbo-sacral in $14(46 \%)$ and sacral in one (3\%). Seventeen patients had associated clubfoot (53\%), 5 strabismus (16\%) and 2 congenital subluxation of the hips (6.4\%).

Morphological evaluation of the CNSwasperformed by cranial US in 20 cases (64.5\%) and CT scan in 11 cases (35.4\%), the exams being carried out, on average, at 1.5 days of life (1-60 days). Thirty patients showed at least some degree of hydrocephalus (97\%) and ten of them had Chiari type II malformation (32\%). There were also other kinds of associated malformations, as seen in Table 1.

Correction of myelomeningocele was in median at four days of life (1 to 44 days). A VPSwasnecessary in 27 of the patients (90\%), in a second surgical step at a median age of 15 days ( $3-270$ days), except for one case who was submitted to the correction of the myelomeningocele and VPS simultaneously. Eighteen patients (58\%) needed at least one reintervention to change the VPS, because of meningitis in 14 of them. The first episode of meningitis occurred at a median age of 21 days ( 4 to 49 days). Among patients without VPS, only 1 had one episode of meningitis. Epilepsy was diagnosed in 7 patients (22.5\%); all had VPS and pre- vious history of meningitis. During the study period, two patients showed a tethered cord and three others, important spinal deformities.

The first neurological evaluation at the outpatient clinic occurred with a median of 48 days of life ( 1 - 570 days), and the patients were followed up from 6 to 68 months (median $=24$ months). Of these, $21(68 \%)$ were evaluated at 1 year of age by Denver II screening test, that showed a greater delay on gross motor area, with a mean performance corresponding to that of a child of 7 months; while in the other areas (fine motor adaptive, language and personal-social) the mean age corresponded to that of a 10 month-old child (see Table 2). The same was seen in 13 patients ( $42 \%$ ) evaluated at 2 years of age (see Table 3 ), for whom the mean age for gross motor function was 6 months lower than for other areas (fine motor adaptive, language and personal-social). The language area, which is better evaluated at this age, did not show any delay.

Urologic evaluation by a pediatric surgeon was done in 19 patients (61\%), with the first exam being performed with a median age of 90 days of life. ( 2 days - 2 years) The patients were followed for 4 monthsup to 60 months (median of 27 months). Twelve patients (38.7\%) had the diagnosis of neurogenic bladder made by urodynamic methods, with a median of 12 months of age (1 - 64 months). The 7 patients without this diagnosis were those who were not submitted to urodynamic study.

Fourteen patients $(45 \%)$ were submitted to imaging studies (USand/or uretrocystography), hydronephrosis and vesico-uretheral reflux were diagnosed in 3 of them. Treatment consisted of intermittent catheterization for these last 3 patients and also for 4 more patients who had important vesicle residues. One patient had been under intermittent catheterization since he was 6 daysold due to early global vesicle formation. The association of anticholinergic medication was necessary for 7 patients and was started at the median age of 26 months ( 4 - 58 months). One patient required the combination of doxozym with oxybutynin and another one the combination of imypramine and oxybutynin. Ten patients had repeated episodes of urinary tract infection (UTI), with half of them being submitted to intermittent catheterization. All patients with the diagnosis of neurogenic bladder were taking a prophylactic antibiotic against UTI.

Six patients died, all before the age of 2 years ( 4 - 20 months): two of meningitis, 1 bronchoaspiration, 
Tabela 4. Main clinical features.

\begin{tabular}{|c|c|c|c|c|c|c|}
\hline $\mathrm{N}$ & Age* & Sex & Lesion level & CNS malformation & $\begin{array}{c}\text { Sphincter } \\
\text { control }\end{array}$ & Ambulation \\
\hline 1 & 68 & $\mathrm{~F}$ & Lumbosacral & & Yes & Yes \\
\hline 2 & 14 & $\mathrm{~F}$ & Lumbosacral & Abscence of 4 th ventricle & No & No \\
\hline 3 & 36 & M & Lumbosacral & Colpocephaly and arqueductal stenosis & No & No \\
\hline 4 & 26 & $\mathrm{~F}$ & Lumbar & Arnold Chiari II and corpus callosum agenesis & No & Yes \\
\hline 5 & 35 & $\mathrm{~F}$ & Lumbar & & No & No \\
\hline 6 & 23 & M & Lumbosacral & & Yes & Yes \\
\hline 7 & 11 & $\mathrm{~F}$ & Lumbar & & No & No \\
\hline 8 & 16 & $\mathrm{~F}$ & Cervical & & No & No \\
\hline 9 & 26 & M & Thoracolumbar & & Yes & Yes \\
\hline 10 & 10 & $\mathrm{~F}$ & Thoracolumbar & Arnold Chiari II & Yes & Yes \\
\hline 11 & 17 & M & Lumbosacral & & No & No \\
\hline 12 & 49 & M & Lumbosacral & & No & Yes \\
\hline 13 & 24 & M & Lumbar & & Yes & Yes \\
\hline 14 & 92 & M & Lumbosacral & Corpus callosum agenesis & Yes & Yes \\
\hline 15 & 18 & M & Lumbosacral & Abscence of 4 th ventricle & No & No \\
\hline 16 & 60 & M & Cervical & Holoprosencephaly & Yes & Yes \\
\hline 17 & 61 & M & Thoracolumbar & & Yes & Yes \\
\hline
\end{tabular}

1 pneumonia and 2 due to an unknown etiology. At present, 17 of the 31 patients are being followed in our service, all of them with good preservation of renal function, 8 have sphincter control and 10 are able to walk (community ambulation) (Table 4).

\section{DISCUSSION}

The prevalence of myelomeningocele of $1.8 \mathrm{ca}$ ses/1000 liveborn neonates found in our service is a little higher than the value reported worldwide, which is around $1 / 1000$, but agrees with the values reported in other South America countries ${ }^{1,2}$. The preponderance of white race found in our study may reflect only the race distribution of our population. The apparent equal gender distribution is false, since if we included the 12 patients born in our maternity who didnot return to neurological evaluation and were excluded of the stu$d y$, the number of females would be higher than the number of males, as has been described by Greene at $\mathrm{al}^{11}$.

In $62 \%$ of our patientsthe level of the lesion was lumbar or lower, thisprobably being one of the rea- sons why many patients were able to walk, although patients with myelomeningocele at high level can also achieve community ambulation when they receive good care, as reported by Charney at all ${ }^{12}$. (Table 4). Environmental factorsmay play a role in the higher risk of the pathologic embryo development, as occurred in 2 cases of gestational diabetes, which is known to act as a cofactor of NTD2. The genetic contribution to malformation of neural tube is suggested by the predominance of its occurrence in the first and second gestation. This emphasizes the importance of prevention of recurrences in families at higher risk to have a second child affected by the same NTD malformation, what can be achieved by simple measures such as the use of folic acid before an during pregnancy ${ }^{3-8}$.

The major reason why part of the patient population was lost to follow-up was the fact that $30 \%$ of the patients' families lived in towns outside Curitiba and its metropolitan region. Most of the mothers had a stable status, since 24 (77.41\%) of them were married and this factor associated with a reasonable educational level are important 
for the cognitive development, as has been demonstrated by Bier et $\mathrm{al}^{13}$.

A prenatal diagnosis by US is difficult to be established, and it usually identifies only the hydrocephalusand their distortions, aswe saw in the present study. To be visualized, the defect must be located in the vertebral column, since the cystic-like sac can not be seen by US ${ }^{14,15}$. There is no agreement about the best route of delivery, but it seems that cesarean section better protects the sac membrane from rupture ${ }^{2,16,17}$. In the present study there were no differences in the number of rupture of the membrane between cesarean section and vaginal delivery. All neonates were full term, in contrast to the literature which reportsa higher prevalence of NTD among premature infants. Also, 20\% of the infants studied were of low birth weight ( $\leq 2500 \mathrm{gr})$, as also reported by Aguiar et $\mathrm{al}^{3}$.

Only one of the patientshad an Apgar score bellow 6 at 5 minutes, a fact excluding the possibility of perinatal asphyxia as the cause of delayed development ${ }^{18}$. Head circumference was within normal values at delivery, although hydrocephalus wasalready present, and decompensation occurred later on, after correction of the myelomeningocele. Hydrocephalus is present in nearly $90 \%$ of the cases at the age of 4 months, as was also the case in the present study ${ }^{13}$. Regarding other complications, Chiari Il malformation, tethered cord, orthopedic and urologic defects were the most preponderant, as also reported in the literature ${ }^{2,15}$.

Although the correction of myelomeningocele should be performed as soon as possible, preferentially within the first 72 hours of life, in some of the present patients the correction was made up to 44 days of life. A ventriculoperitoneal shunt, indicated to the patientswith hydrocephalus, was performed in $90 \%$ of them in a second stage in order to reduce the chance of CNS infection ${ }^{2,19}$. Even so, however, episodes of meningitis were responsible for reinterventions in order to change the VPS in 14 patients, usually before one month of itsplacement. The large number of CNS infections that occurred in our sample could be mostly explained by the delay in correcting the myelomeningocele in many of them (after 72 hours) 2,20-22. The mortality rate was relatively low despite delays in correcting the NTD, thanks to the use of prophylactic antibiotic ${ }^{20,22}$. The association of epilepsy and myelomeningocele in the present study was probably related to the presence of VPS that compensates for hydrocephalus, plus previousepisodes of meningitis, also mentioned by other authors ${ }^{23-25}$.

Denver II Test showed that the major delay in the developmental milestone of our patientsoccurred in the gross motor area, directly affected by the myelomeningocele. The intelligence quotient (IQ) was not available for most of the patients and therefore it was impossible to assess their cognitive level but, based on Fobe et al, a normal IQ can be achieved up to $80 \%$ of the patients ${ }^{21}$. Denver II Screening Test in children at risk, in which there is up to one failure at the age of 2 years, was found an IQ $>80$, by WPSSI-R, in $70 \%$ of these children at the age of 5 years, according to Frankenburg et al. ${ }^{10}$ and Bruck et al. (personal comunication). The language area, which isbetter evaluated at 2 yearsold did not show any delay, indicating that the problem mainly concerns the gross motor area.

It was an agreeable surprise to observe that, although the diagnosis of bladder dysfunction wasmade with a delay in many of the patients, all showed preservation of renal function, and many of them were socially competent (dry for 3 hours) (Table 4). We would like to emphasize that the literature recommendsintermittent catheterization during the first year of life, and even starting at birth because this procedure does not involve major side effects, and is of great benefit. Thus, it should be routinely used even in the absence of bladder dysfunction ${ }^{26-28}$.

We could see that many of the motherslooked for urologic evaluation only latter on, because of their concern about their children being unable to leave diapers at the age supposed to do it.

The mortality rate in our sample was $19 \%$, greater than that described by Brau at al. (10-15\%) and all of them happened before 2 years, which is the age of greater risk ${ }^{20}$.

In conclusion the present study represents only a small sample of children with myelomeningocele and it is necessary more studies made in other centers in order to have a better idea of how are the Brazilian children with this pathology. been managed. We would like to mention that the Brazilian government is planning to enrich wheat flour with folic acid, as a prophylactic measure to prevent pregnant women from having an offspring with myelomeningocele ${ }^{29}$. These children if well and appropriately managed by multidisciplinary team can have a better quality of life. 


\section{REFERENCES}

1. Grillo E, Silva RJM. Defeitos do tubo neural e hidrocefalia congênita: por quê conhecer suas prevalências? J Pediatria 2003;79:105-106.

2. Northrup H, Volcik KA. Spina bifida and other neural tube defects. Curr Probl Pediatr 2000;30:315-337.

3. Aguiar MJB, Campos AS, Aguiar RALP, et al. Defeitos de fechamento do tubo neural e fatores associados em recém-nascidos vivos e natimortos. J Pediatria 2003;79:129-134.

4. Czeizel AE, Dudas I. Prevention of the first occurrence of neural-tube defects by periconceptional vitamin supplementation. N Engl J Med 1992;327:1832-1835.

5. Czeizel A E. Prevention of congenital abnormalities by periconceptional multivitamin supplementation. BMJ 1993;306:1645-1648.

6. Werler MM, Shapiro S, Mitchell AA. Periconceptional folic acid exposure and risk of ocurrent neural tube defects. JAMA 1993;269:1257-1261.

7. Daly S, Mills JL, Molloy AM, Conley M, Lee YJ. Minimum effective dose of folic acid for food fortification to prevent neural-tube defects. Lancet 1997;350:1666-1669.

8. Kadir RZ, Sabin C, Whitlow B, Brockbank E, Economides D. Neural tube defects and periconceptional folic acid in England and Wales: retrospective study. BMJ 1999;319:92-93.

9. Glascoe FP, Byrne KE, Ashford LG, Johnson KL, Chang B, Strickland B. Accuracy of the Denver II in developmental screening. Pediatrics 1992;89:1221-1225.

10. Frankenburg WK, Dodds J, Archer P, Shapiro H, Bresnick B. The Denver II: a major revision and restandardization of the Denver Developmental Screeneing Test. Pediatrics 1992;89:91-97.

11. Greene WB, Terry RC, DeMasi RA, Herrington RT. Effect of race and gender on neurological level in myelomeningocele. Dev Med Child Neurol 1991;33:110-117.

12. Charney EB, Melchionni JB, Smith DR. Community ambulation by children with myelomeningocele and high-level paralysis. J Pediatr Orthop 1991;11:579-582.

13. Bier JB, Morales Y, Liebling J, Geddes L, Kim E. Medical and social factors associated with cognitive outcome in individuals with myelomeningocele. Dev Med Child Neurol 1997;39:263-266.

14. Dumas JL, Pascaud E, Novello G, Ronayette D, Rousseau J. Place de l' écho-encéphalographie dans les myéloméningoceles. Ann Pédiatr (Paris) 1992;39:53-55.

15. Skari H, Bjornland K, Bjornstad-Ostensen A, Haugen G, Emblem R.
Consequences of prenatal diagnosis: a preliminary report on neonates with congenital malformations. Acta Obstet Gynecol Scand 1998;77:635-642.

16. Merril DC, Goodwin P, Burson JM, Sato Y, Williamsom R, Weiner CP. The optimal route of delivery for fetal meningomyelocele. Am J Obstet Gynecol 1998;179:235-240.

17. Hill AE, Beattie F. Does cesarean section delivery improve neurological outcome in open spina bifida? Eur J Pediatr Surg 1994;4(Suppl 1):S32-S34

18. Comitee on Fetus and Newborn of American Academy of Pediatrics and Comitee on Obstetric Practice of American College of Obstetricians and Gynecologists. Use and abuse of the Apgar Score. Pediatrics 1996;98:141-142.

19. Rolle U, Gräfe G. About the rate of shunt complications in patients with hydrocephalus and myelomeningocele. Eur J Pediatr Surg 1999;9(Suppl 1):S51-S52.

20. Brau RH, Rodríguez R, Ramírez MV, González R, Martínez V. Experience in the management of myelomeningocele in Puerto Rico. J Neurosurg 1990;72:726-731.

21. Fobe J, Rizzo AMPP, Silva IM et al. QI em pacientes com hidrocefalia e mielomeningocele. Arq Neuropsiquiatr 1999;57:44-50.

22. Charney EB, Melchionni JB, Antonucci D. Ventriculitis in newborns with myelomeningocele. AJDC 1991;145:287-290.

23. Hack CH, Enrile BG, Donat JF, Kosnik E. Seizures in relation to shunt dysfunction in children with meningomyelocele. J Pediatr 1990;116:57-60.

24. Noetzel MJ, Blake JN. Prognosis for seizure control and remission in children with myelomeningocele. Dev Med Child Neurol 1991;33:803-810.

25. Talwar D, Baldwin MA, Horbatt CI. Epilepsy in children with meningomyelocele. Pediatr Neurol 1995;13:29-32.

26. Churchill BM, Abramson RP, Wahl EF. Dysfunction of the lower urinary and distal gastrointestinal tracts in pediatric patients with know spinal cord problems. Pediatr Urol 2001;48:1587-1629.

27. Kaefer M, Pabby A, Kelly M, Darbey M, Bauer SB. Improved bladder function after prophylactic treatment of the high risk neurogenic bladder in newborns with myelomeningocele. J Urol 1999;126:1068-1071.

28. Wu H, Baskin LS, Kogan BA. Neurogenic bladder dysfunction due to myelomeningocele: neonatal versus childhood treatment. J Urol 1997:157:2295-2297.

29. Agência Nacional de Vigilância Sanitária. Resolução - RDC n ${ }^{\circ} 344$, de 13 de dezembro de 2002. Diário Oficial da União de 18/12/2002. http:/ /www.anvisa.gov.br/legis/resol/2002/344_02rdc.htm. 